\title{
Geste des Bretuns ou Harley Brut, B. Barbieri (éd.)
}

\author{
Maria Colombo Timelli
}

\section{(2) OpenEdition}

\section{Journals}

\section{Édition électronique}

URL : http://journals.openedition.org/studifrancesi/9888

DOI : 10.4000/studifrancesi.9888

ISSN : 2427-5856

\section{Éditeur}

Rosenberg \& Sellier

\section{Édition imprimée}

Date de publication : 1 août 2017

Pagination : 333

ISSN : 0039-2944

\section{Référence électronique}

Maria Colombo Timelli, « Geste des Bretuns ou Harley Brut, B. Barbieri (éd.) », Studi Francesi [En ligne], 182 (LXI | II) | 2017, mis en ligne le 18 octobre 2017, consulté le 06 janvier 2021. URL : http:// journals.openedition.org/studifrancesi/9888; DOI : https://doi.org/10.4000/studifrancesi.9888

Ce document a été généré automatiquement le 6 janvier 2021.

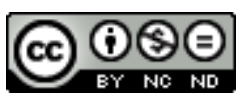

Studi Francesi è distribuita con Licenza Creative Commons Attribuzione - Non commerciale - Non opere derivate 4.0 Internazionale. 


\title{
Geste des Bretuns ou Harley Brut, B. Barbieri (éd.)
}

\author{
Maria Colombo Timelli
}

\section{RÉFÉRENCE}

Geste des Bretuns ou Harley Brut, Édition critique par Beatrice BARBIERI, Paris, Classiques Garnier, 2015, «Textes littéraires du Moyen Âge» 37, 276 pp.

1 Unique traduction en alexandrins de l'Historia regum Britanniae de Geoffroy de Monmouth, cette Geste des Bretuns (appelée Harley Brut par Bryan Blakey, du nom du manuscrit de la British Library) nous est parvenue dans cinq fragments couvrant au total quelque 3500 vers, qui correspondent à cinq sections de l'Historia, allant du livre 73 au livre 167 avec des lacunes: l'édition de Beatrice Barbieri - issue de sa thèse de doctorat soutenue à Sienne en 2011 - est la bienvenue, car elle met enfin à la disposition des lecteurs la totalité du texte.

2 L'Introduction présente d'abord la source, sa tradition manuscrite et ses versions françaises, pour s'arrêter plus longuement sur les manuscrits de la Geste (London, B.L., Harley 1605a; Lincoln, Cathedral Library, 104; London, B.L., Add. 45103), tous les trois du XIII ${ }^{e}$ siècle. Suit l'étude de la technique de traduction adoptée par l'auteur anonyme, qui, excellent connaisseur du latin et fidèle à la source latine (surtout dans les quelque 600 vers des Prophéties de Merlin), se permet néanmoins des abrègements et des amplifications, ceux-ci notamment dans la section arthurienne; il connaît et adopte la manière des chansons de geste, dont on retrouve certains traits - vers d'intonation en début de laisse, laisses parallèles, style formulaire - et choisit un mètre relativement nouveau pour la matière épique à une époque de transition. Tant la langue que la provenance des manuscrits confirment l'origine anglo-normande de la Geste, qui peut être datée de la seconde moitié du XII ${ }^{\mathrm{e}}$ siècle. Dans une partie plus proprement philologique, B.B. discute les rapports entre les trois mss pour la section commune - les Prophéties - mais ne peut affirmer en toute certitude l'existence d'un archétype 
français: dans une telle situation, la source latine constitue un texte de contrôle essentiel pour la reconstitution du texte critique.

3 La Note sur la langue s'articule en 13 points qui portent tous - sauf le dernier, sur les mots préfixés - sur la phonétique des mots en rime; un paragraphe à part concerne la graphie du manuscrit Harley. La Note sur la versification analyse les alexandrins et souligne surtout l'impossibilité de restituer des vers métriquement parfaits en anglonormand. Les Principes d'édition séparent les parties transmises par un seul manuscrit et celles qui se lisent dans deux voire dans les trois copies.

4 Les cinq fragments de la Geste sont édités avec soin et précision: les interventions, peu nombreuses, sont toutes signalées dans l'apparat et éventuellement commentées dans les notes finales; celles-ci contiennent aussi de précieux renvois à la source et des éclaircissements sur le contenu. Au vu de la difficulté du texte, on aurait peut-être souhaité un glossaire un peu plus riche (quelque 400 lemmes au total); pour ne donner que quelques exemples, on n'y trouvera aucun de ces mots, tous contenus dans la première laisse du deuxième fragment (p. 139): trencher (quant li munz fud trenché, v. 2), peruns (dous granz cavez p., v. 4), lesçuns (si dit la l., v. 6), tençuns (griefs fud la t., v. 12), serjanz (v. 11), sermuns ([Merlin] cumençad ses s., v. 17), guai (G. al ruge dragun, v. 19). Le recours à l'Anglo-Norman Dictionary en ligne s'avèrera donc indispensable pour tout lecteur non spécialiste de cette langue.

5 S'ajoutent les compléments habituels: bibliographie (pp. 255-263), index des noms (pp. 265-269) et des toponymes (pp. 271-273). 